\title{
Research on Dilemma and Countermeasures of Core Technology Breakthroughs in China's High- End Equipment Manufacturing Industry
}

\author{
Weiqing LI \\ Zhejiang International Studies University \\ Hangzhou, China \\ 88924381@163.com
}

\begin{abstract}
On the basis of the existing research lite rature, this paper points out the urgency of core technology breakthrough in China's high-end equipment manufacturing industry, and deeply analyzes the problems existing in the core technology breakthroughs of high-end equipment manufacturing industry. Then from three aspects of planning mechanism, distribution incentive mechanism and commercialization path, this paper puts forward the countermeasures for the breakthrough of the core technology in the high-end equipment manufacturing industry in China. Government departments should establish the planning mechanism for the breakthrough of industrial core technology and efficiency oriented incentive mechanism for resource allocation. Enterprises should also push their own new products into commercialization and improve the commercialization path of core technology breakthrough.
\end{abstract}

Keywords-High-End Equipment; Manufacturing Industry; Core Technology Breakthrough; Dilemma; Countermeasures

\section{INTRODUCTION}

Vigorously cultivating and developing high-end equipment manufacturing industry is the inevitable requirement to enhance the core competitiveness of manufacturing industry, it is also an inevitable choice for China to participate in international competitiveness and turn to manufacturing power. With the rapid development of China's high-end equipment manufacturing industry, it's total amount of import and export shows a trend of rapid growth, However, there is still a big gap compared with manufacturing power. At present, the international market share of China's high-end equipment is low, and the ability of independent innovation is still weak, the technical reserve of independent intellectual property rights is also low. The key parts of the core equipment, system software and key technologies depend on imports which are controlled by others. In order to cope with the new round of technological revolution and industrial transformation, we will seize the commanding heights of future competition. Therefore, to enhance the innovation capability and international competitiveness of high-end equipment manufacturing industry is a necessary way for China to realize manufacturing power. Duo Jie (2012)found that the main reason for the low efficiency of technological innovation of China's equipment manufacturing industry was that the innovation resources were not fully utilized. The core technology of China's high-end equipment manufacturing industry urgently needs breakthroughs. This paper will analyze the main obstacles of core technology breakthroughs in the high-end equipment manufacturing industry, and explore the relevant countermeasures for the core technology breakthrough of China's high-end equipment manufacturing industry.

\section{LITERATURE REVIEW}

Many scholars have researched on the high-end equipment manufacturing industry from the perspective of technological innovation and competitiveness. Zhang Mir and others (2004) analyzed the supporting conditions for upgrading the equipment manufacturing industry from the perspective of technology and system, they proposed to promote the upgrading of equipment manufacturing industry through effective interaction between technological innovation and institutional innovation[1]. Li Shijie (2004), by constructing a cluster network structure framework, explored the reasons for the linkage of equipment manufacturing cluster, the characteristics of the network of factors and manufacturing agglomeration[2]. Ding Yaomin (2008) believed that technological innovation capability was a fundamental problem between China's equipment manufacturing industry and the international advanced manufacturing industry, the main factors that affect its technological innovation ability were innovation input, innovation output and innovation environment[3].Through analyzing the bottleneck of the international competitiveness of China's high-end equipment manufacturing industry, Zhang Xiaodong et al. (2015)pointed out that large scale equipment enterprises should change their R\&D mode, We should encourage the demonstration effect of the first set of equipment applications and strengthen the technology talents reserve of high-end manufacturing[4]. Dujie(2012) thought that China's high-end equipment manufacturing industry needed to shift from inter firm competition to value chain competition, and through comparison found that China's rail transit equipment and marine engineering equipment had certain competitive advantages, but aerospace equipment was lack of competitive advantages[5]. Fu Baozong (2013) thought that the main factors that affected the core competitiveness of China's equipment manufacturing industry were factor supply, technical talents and government management system and mechanism[6]. 
From the research above, we found that many scholars researched the high-end equipment manufacturing industry from the perspective of technological innovation and competitiveness, and their researches were mainly based on qualitative research and quantitative research. However, the current literature on core technology breakthroughs in high-end equipment manufacturing industry is scarce.

\section{Dilemmas AND OBSTACLES}

\section{A. Long period and big resistance of technical breakthrough}

In general, it takes a long time to achieve technological breakthrough and innovation. The time cycle of product development in different industries is different and the time from technology design to trial production to market development is also different. The time required depends on various factors of industrial characteristics. Because the highend equipment manufacturing industry is the technology intensive industry, even from product design, technology development to product trial production and customer support, the technology breakthrough period of high-end equipment manufacturing is longer, and the results are difficult to predict.

Technological innovation requires huge capital investment, because the duration of the research cycle is long, investors need to wait longer and patiently to see investment returns. If investors are eager for quick success and instant benefits, they often disrupt the capital needed for technological breakthrough, which make technology difficult to breakthrough. At the same time, technological breakthroughs often force a fundamental shift in the way employees work. Enterprises will try to keep the original technology and market, and apply the breakthrough new technology slowly.

\section{B. Core technology breakthroughs lack competitive advantage}

The core technology of China's high-end equipment manufacturing industry is generally lagging behind that of developed manufacturing countries, with insufficient original innovation. China's high-end chip 90\% relies on imports. In 2017, China's high-end chip imports reached nearly 100 billion US dollars. Some of the key components are also dependent on imports; the lack of core technology and key components directly restricts the comprehensive technological level of China's high-end equipment manufacturing industry. This reflects the relatively weak capability of high-end equipment R\&D in China. Nowadays, whether it's integrated circuit, highspeed rail, automobile or large aircraft industry, many high-end equipment manufacturing sectors in China lack core technologies. The industry does not grasp the commanding heights of the industry's international standards, and lacks the discourse right of industry standard. Compared with the foreign manufacturing powers, the technological gap of some patents in China is also obvious. In the patent products, the tacit knowledge of the high-end equipment manufacturing is not enough. This is related to the tendency to repurchase and neglect R\&D in China.

The weak international competitiveness of the core technology of China's high-end equipment manufacturing industry is also reflected in the inadequate development of the division and collaboration network of high-end equipment manufacturing enterprises. It is difficult to integrate the local resources and knowledge based on the resource advantages of different countries and the large number of local suppliers. This makes China's high-end equipment manufacturing industry chains lack synergy; it is difficult to develop the correlation effect and technology spillover of high-end equipment manufacturing industry.

\section{The commercialization of core technology is difficult}

Because high-end equipment has long been monopolized by foreign countries, the same equipment in China lacks core technology, independent innovation capability of enterprises is low, and technology relies on imports for a long time. The upgrading of the main products such as CNC system is finished by importing technology from abroad, and the market share is low. The basic components of high-end equipment manufacturing industry have low performance and low quality, and the information level of manufacturing process is relatively low. At present, China's high-end equipment manufacturing industry has problems of regional assimilation and independent brands.

The core technological breakthroughs are inseparable from the support of all kinds of technical talents. The loss and fault of specialized talents in high-end equipment manufacturing industry have affected the development of industrial R \& D capability, and the problem of cooperative R\&D system has not been solved. At the same time, the government departments have not yet introduced the universal support policy and tax support system for high-end equipment core technology research and development. The technology application ability of high-end equipment commercialization is relatively short, which leads to the difficulty of realizing large-scale commercial application of independent design equipment.

\section{RECOMMENDATION}

\section{A. Setting up the planning mechanism for the breakthrough of industrial core technology}

Strengthening the government's plan for the development of high-end equipment manufacturing industry. It should establish a planning mechanism for core technology breakthrough, and strengthen the innovative planning ability of high-end equipment manufacturing industry. First of all, the government guides enterprises to systematically analyze the market demand of industrial development and identify the direction of R\&D and technological breakthroughs. Secondly, it proposes the industrial technology breakthrough plan to systematically analyze the technical categories and technical characteristics of the breakthrough by government organizations or enterprises. Thirdly, seriously organize research team and participants, identify the best R\&D personnel for different specific industry technologies, and form research teams for technological development and breakthroughs. Finally, formulate relevant financial policy planning measures, give financial support to the implementation of core technology R\&D enterprises, and achieve core technological breakthroughs.

\section{B. Establishing efficiency oriented innovation resource incentive mechanism}

The establishment of distribution incentive mechanism can promote the enthusiasm and initiative of scientific research 
personnel, and improve the efficiency of technological innovation. Specifically, we should continue to deeply reform the equipment manufacturing enterprises, improve the incentive mechanism of technological innovation, and protect the intellectual property rights of innovation, identify the benefit distribution of the technical breakthroughs. Make clear the goal of technological breakthrough and the process of evaluating innovation breakthrough, and play the role of incentive mechanism to the greatest extent. The goal of innovation should inspire team members, stimulate the enthusiasm of team members, and help the team to better understand the strategic intentions of senior managers. Core technical breakthroughs require team members to work together; this requires a fair team member evaluation system to link the value of the technological breakthrough with the innovation team award directly to form a long-term result sharing mechanism. At the same time, enterprises should established a perfect promotion mechanism, complete the career development plan of technical personnel, set the chief engineer and the leading position of the $R \& D$ project, and stimulate the enthusiasm of the technical R\&D personnel.

\section{Improving the commercialization path of core technology breakthrough}

Conduct new product market research and guide enterprises to independently develop R\&D commercial products by market means, and push new products to commercialization. According to the specific requirements of the project, the enterprise should build a breakthrough innovation team and ensure the funds and equipment needed for the research and development of the innovation team, and promote innovation team to carry out the work. Actively building open innovation networks with core technology diffusion, through which the core technology will flow to the partners, competitors, consumers and suppliers, so as to promote the commercialization of core technology. This not only promotes core technology diffusion and commercialization, but also obtains royalties and profits through spillover of technology. At the same time, through the introduction of inclusive policy, the government departments will enhance the market expectations of independent design equipment, and strengthen the demonstration effect of the first set of high-end equipment in China to enhance market confidence. Through the implementation of the compensation mechanism for the first set of high-end equipment, it ensures the use of high-end equipment by independent research and development, and coordinates equipment manufacturing enterprises to open the domestic market.

\section{CONCLUSION}

In summary, there are some dilemmas and obstacles in the core technology breakthrough of China's high-end equipment manufacturing industry, including long period and big resistance of technical breakthrough, core technology breakthroughs lacking competitive advantage and the commercialization of core technology being difficult. However, the core technological breakthroughs are inseparable from the support of all kinds of technical talents.

Facing the main dilemmas and obstacles of core technology breakthroughs in high-end equipment manufacturing industry, government departments and enterprises should take measures and countermeasures. Government departments should establish the planning mechanism for the breakthrough of industrial core technology and efficiency oriented incentive mechanism for resource allocation. Enterprises should push their own new products into commercialization and improve the commercialization path of core technology breakthrough. Especially enterprises should build a breakthrough innovation team and ensure the funds needed for the research and development of the innovation team, enterprises also further improve the incentive mechanism of technological innovation and protect the intellectual property rights of innovation.

\section{REFERENCES}

[1] Zhang Mir, Jiang Shi Song. Innovation interaction and upgrading of manufacturing industry [J]. Science and Technology Management, 2004, (10).

[2] Li Shijie. Research and demonstration of the network structure of equipment manufacturing cluster [J]. Management World, 2004, (12).

[3] Ding Yaomin. Strive to promote technological innovation in the equipment manufacturing industry [J]. China Economic and Trade Guide, 2008, (6).

[4] Zhang Xiaodong, Cai Shukai, Zhu Yu. Analysis of the bottleneck breakthroughs in the international competition of China's high-end equipment manufacturing industry [J]. Journal of Fujian Agriculture And Forestry University,2015,18 (5): 57-62.

[5] Dujie, Liu Yong, Wang Yanhong. Empirical research on technological innovation efficiency of equipment manufacturing industry based on DEA improved model [J]. Progress in Science and Technology and Countermeasures, 2012 (6): 65-69.

[6] Fu Baozong, Current characteristics and influencing factors of competitiveness of China's equip ment manufacturing industry [J]. China Economic and trade guide.2013, (7): 51-54. 